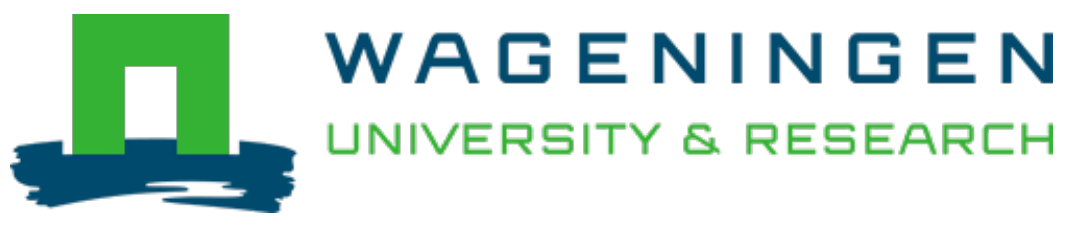

\title{
Applications of radiative transfer models to greenhouse vegetation
}

Acta Horticulturae

Vilfan, N.; Dieleman, J.A.; Elings, A.; Polder, G.

https://doi.org/10.17660/ActaHortic.2020.1296.46

This article is made publicly available in the institutional repository of Wageningen University and Research, under the terms of article $25 \mathrm{fa}$ of the Dutch Copyright Act, also known as the Amendment Taverne. This has been done with explicit consent by the author.

Article $25 \mathrm{fa}$ states that the author of a short scientific work funded either wholly or partially by Dutch public funds is entitled to make that work publicly available for no consideration following a reasonable period of time after the work was first published, provided that clear reference is made to the source of the first publication of the work.

This publication is distributed under The Association of Universities in the Netherlands (VSNU) 'Article 25fa implementation' project. In this project research outputs of researchers employed by Dutch Universities that comply with the legal requirements of Article $25 \mathrm{fa}$ of the Dutch Copyright Act are distributed online and free of cost or other barriers in institutional repositories. Research outputs are distributed six months after their first online publication in the original published version and with proper attribution to the source of the original publication.

You are permitted to download and use the publication for personal purposes. All rights remain with the author(s) and / or copyright owner(s) of this work. Any use of the publication or parts of it other than authorised under article $25 \mathrm{fa}$ of the Dutch Copyright act is prohibited. Wageningen University \& Research and the author(s) of this publication shall not be held responsible or liable for any damages resulting from your (re)use of this publication.

For questions regarding the public availability of this article please contact openscience.library@,wur.nl 


\title{
Applications of radiative transfer models to greenhouse vegetation
}

\author{
N. Vilfana, J.A. Dieleman, A. Elings and G. Polder \\ Wageningen University \& Research, Business Unit Greenhouse Horticulture, Droevendaalsesteeg 1, 6708 PB \\ Wageningen, The Netherlands.
}

\begin{abstract}
In greenhouse horticulture, efficiency of climate control and plant protection can be improved by having an accurate impression of plant status, such as photosynthesis or chemical composition. Recent advances in remote sensing technologies have brought about a range of innovations in precision agriculture, with the potential for adaptation to greenhouses. Simple, traditionally used indices employ only one or two spectral bands, in which the contributions of various pigments and leaf or canopy structure can highly overlap. Consequently, such indices may be insufficient for applications. State-of-the-art models have been developed that can better interpret hyper- and multispectral leaf and canopy imagery by employing the biochemical and radiative transfer properties of vegetation. An example is the soil-canopy observation of photosynthesis and energy balance (SCOPE) model, which was developed specifically for crop canopies. Here we present one of the pillars of SCOPE, the leaf radiative transfer (RT) model Fluspect. Fluspect simulates leaf chlorophyll fluorescence, reflectance and transmittance spectra. The model can be inverted to obtain estimates of leaf chlorophylls, carotenoids, anthocyanins, xanthophyll epoxidation, water and dry matter content. Moreover, it can be linked to a model for leaf photosynthesis and when inverted, provide a method to estimate photosynthesis directly from leaf spectral information. We test the model against a tomato data set, with measured hyperspectral images, chlorophyll, sugar, acid, starch, dry matter content and nutrients. The first study of the data set, using partial least square regression, showed that hyperspectral images have a high correlation with important fruit and leaf compounds. We compared these results to Fluspect retrievals and conventional vegetation indices. In the paper, we discuss the potential added value of using RT models in greenhouse horticulture.
\end{abstract}

Keywords: hyperspectral imagery, leaf reflectance, Fluspect, pigment content, tomato

\section{INTRODUCTION}

From the beginning of earth observation, i.e., gaining information of Earth's physical, chemical and biological characteristics by remote sensing methods, the interpretation of the information hidden in the images of vegetation has been of great interest to scientist in many different scientific fields. By being able to remotely and therefore non-destructively determine plant biophysical characteristics, costly and time-consuming destructive (ground) measurements can be avoided.

Different methods are available for interpretation of vegetation images. The simplest method is the use of indices. One of the best known and used, but also the oldest index is NDVI or normalized difference vegetation index. NDVI is also known as the 'greenness index' and it simply identifies the red/infrared ratio. All indices usually consist of only a few wavelengths: a biophysically significant and a reference wavelength (Sims and Gamon, 2002; Mahlein et al., 2013). A more advanced methods are the mechanistic radiative transfer (RT) models. Leaf and canopy RT models are based on a physical description of light absorption and scattering by leaves or canopies, and are therefore useful in designing reflectance indices, performing sensitivity analyses, and developing inversion procedures to accurately retrieve biophysical

aE-mail: nastassia.rajhvilfan@wur.nl 
properties from images of leaves or plants. Among all the codes published so far, the SAIL canopy bidirectional reflectance model and the PROSPECT leaf optical properties model are the most popular (Jacquemoud et al., 2009). In the last decade, the canopy model SAIL was combined with an upgraded version of the leaf model PROSPECT, called Fluspect (Vilfan et al., 2016), into the soil-canopy observation of photosynthesis and energy balance (SCOPE) model (Van der Tol et al., 2009).

Despite the seemingly different methodology, the underlying 'ground truth' remains the same: the leaves contain absorbing compounds that absorb photons with a specific energy, as illustrated in Figure 1. Some of these properties change in a matter of days, such as the photosynthetic pigments chlorophylls, and some in a matter of hours or even seconds, such as leaf water content or photosynthetic efficiency (Stylinski et al., 2002). Two particularly promising indicators of leaf photosynthesis and potential 'stress' are chlorophyll fluorescence and the photochemical reflectance index (PRI) (Garbulsky et al., 2011; Ač et al., 2015). Their potential has led to the selection of the FLuorescence Explorer (FLEX) satellite mission: a dedicated mission of the European Space Agency (ESA) that will launch in the next few years (Drusch et al., 2017).

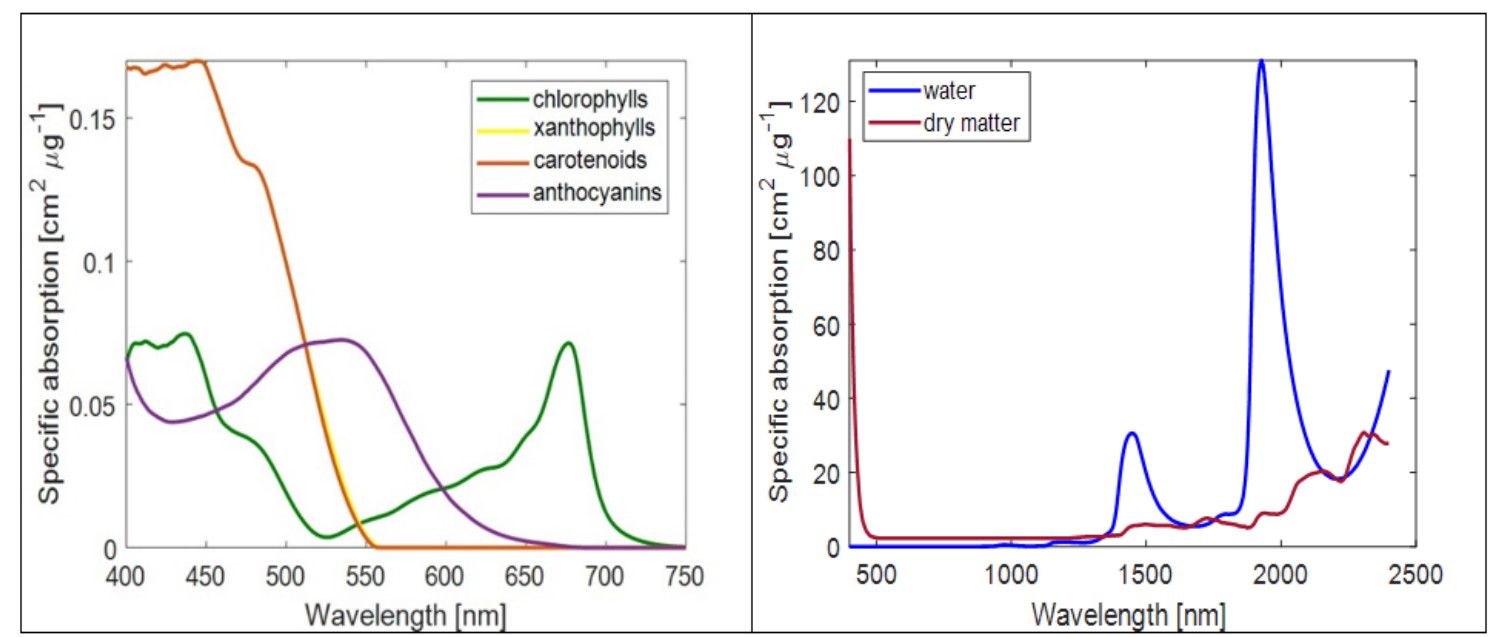

Figure 1. Specific absorption coefficients of various leaf compounds as used in the leaf radiative transfer model Fluspect. Left panel: absorption of pigments absorbing in the visible spectrum (VIS). Right panel: absorption of water and dry mater, shown over the VIS and near-infrared (NIR) spectrum.

The field of precision agriculture is in step with these fast developments (Tremblay et al., 2012; Wieneke et al., 2016), where unmanned aerial vehicles (UAVs) and drones carrying cameras are becoming a standard for crop monitoring. From there only a small step is needed to apply the same knowledge into the greenhouses: the principles and the crop information remain the same, while the imaging level is downscaled to the leaves and canopies.

In this paper, we present the leaf RT model Fluspect and test it on the images of greenhouse grown tomato leaves. We compare the results to conventional methods and further discuss the applicability, advantages and disadvantages of RT models.

\section{MATERIALS AND METHODS}

\section{Hyperspectral images of tomato leaves}

For our analysis, we used hyperspectral images, taken on fully-developed leaves of greenhouse grown tomatoes at the end of May 2017 (plant date September 9, 2016; Dieleman et al., 2018). The tomato plants were grown in a greenhouse compartment of $144 \mathrm{~m}^{2}$. To get a range of differences in pigment and sugar contents of leaves, five cultivars were grown and later sampled: 'Foundation', 'Extension', 'NUN 09204', 'NUN 09149' (cocktail tomato) and 


\section{'Competition' (cherry tomato).}

Selected leaves measured with two hyperspectral cameras: a VNIR camera, measuring in the visible (VIS) and the near-infrared range (NIR) from 400 to $1000 \mathrm{~nm}$, and a NIR camera, measuring from 900 to $1700 \mathrm{~nm}$. After the images were taken, the samples were collected from the same leaves for destructive measurements of chlorophyll, carotenoid content, dry matter and sugar content. In this study, we used 100 leaf samples with both hyperspectral and destructive information of chlorophylls and carotenoid concentrations for each leaf.

\section{Estimation of pigment contents with Fluspect}

The hyperspectral image of each leaf was averaged to obtain one reflectance spectrum per leaf. This spectrum was used in the model inversion. A trust-region algorithm was applied to quantify a cost function. The algorithm provided optimised chlorophyll and carotenoid content once for each leaf by fitting the modelled reflectance spectrum to the measured spectrum. The stopping criteria were an insignificant change in parameter values and a minimum improvement in the cost function; iteration stopped when one of these criteria were met. We plot the estimated pigment contents against the destructively measured values and evaluate the goodness-of-fit by calculating the root mean-squared error (RMSE) and the coefficient of determination $\left(\mathrm{R}^{2}\right)$.

For a further evaluation and demonstration, we calculated the indices NDVI and PRI as

$$
\begin{gathered}
N D V I=\frac{R_{850}-R_{680}}{R_{850}+R_{680}}(\text { Peñuelas et al., 1994) } \\
P R I=\frac{R_{531}-R_{570}}{R_{531}+R_{570}} \text { (Gamon, Peñuelas and Field, 1992) }
\end{gathered}
$$

and plotted them against the pigments captured by their equations: chlorophylls for NDVI and carotenoids for PRI.

\section{RESULTS AND DISCUSSION}

In Figure 2 we show a few representative reflectance spectra of tomato leaves, with typical low reflectance (high absorption) in the visible (VIS, 400-700 $\mathrm{nm}$ ) part and a high reflectance in the NIR.

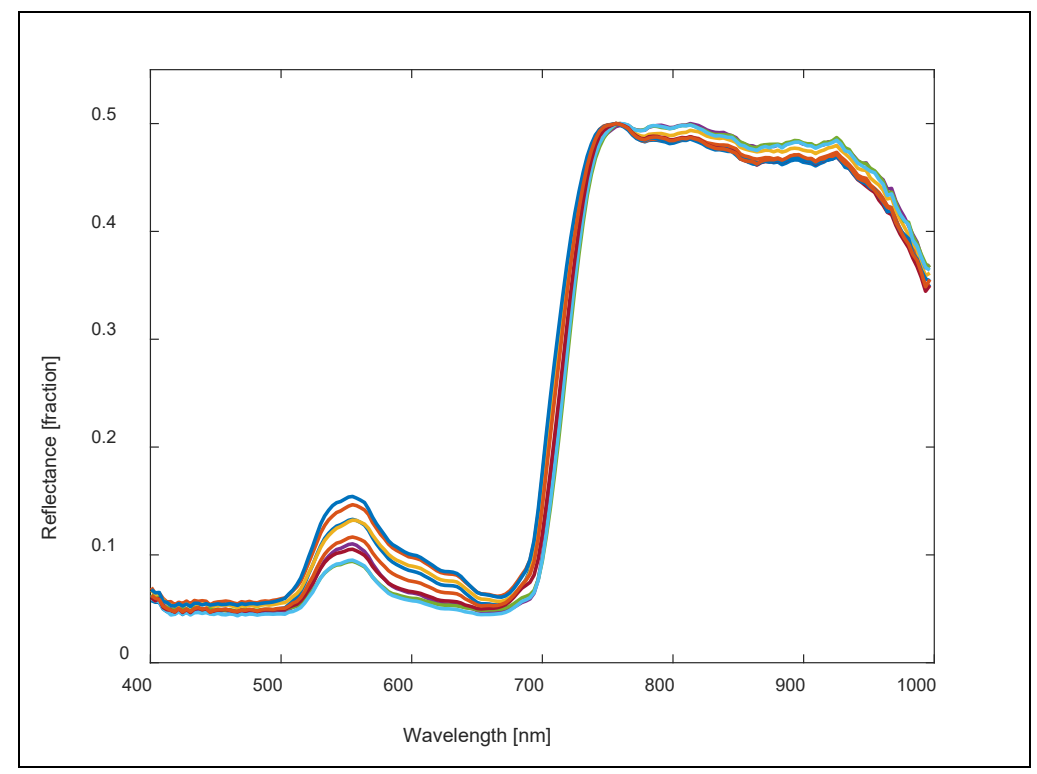

Figure 2. An example of the leaf spectra over the VIS and NIR range. Ten representative reflectance spectra of 10 different leaves are plotted. 
Pigment concentrations, estimated with Fluspect, plotted against the destructively measured values are shown in Figure 3 . Both pigments were estimated well, particularly chlorophyll concentration $\left(\mathrm{R}^{2}=0.93\right)$. In the original report (Dieleman et al., 2018), the data were analysed using the partial least square regression (PLS). PLS analysis resulted in slightly higher estimates: $\mathrm{R}^{2}>0.97$ for chlorophylls and $\mathrm{R}^{2}=0.90$ for carotenoids. Nonetheless, one big advantage of radiative transfer models is their general applicability due to the physical description they are based on. PROSPECT and Fluspect have been thoroughly validated and were shown to generate similarly accurate pigment estimations over a range of species (Demarez, 1999; Féret et al., 2017).

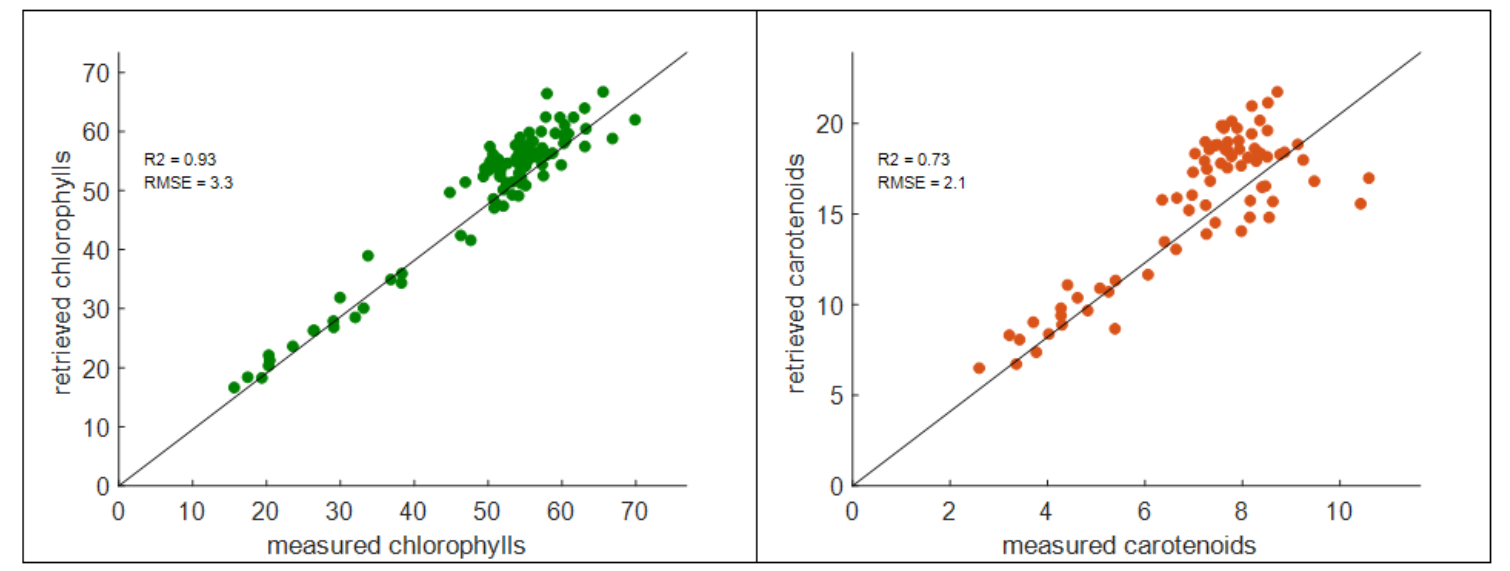

Figure 3. Optimised Fluspect parameters versus the measured (from destructive sampling) equivalents: (left) chlorophyll and (right) carotenoid concentrations (both in $\mathrm{g}$ $\mathrm{cm}^{-2}$ ). Parameters were optimised to best reproduce measured reflectance.

Apart from carotenoids and chlorophylls, as indicated in Figure 1, Fluspect is also able to simulate leaf water content, dry matter, thickness, anthocyanins, xanthophyll cycle pigments and chlorophyll fluorescence efficiency. All these parameters were also estimated, however, due to a lack of destructive measurements for these features, we could not run a comparison. Because of the nature of the RT models, absorption features can always be added, for example, recently anthocyanins (Féret et al., 2017), chlorophyll fluorescence (Vilfan et al., 2018) and xanthophyll cycle (Vilfan et al., 2018) pigments were added, and chlorophylls were separated into chlorophyll a and b (Zhang et al., 2017). Of particular interest to the greenhouse horticulture would be for example the addition of the sugar absorption spectrum and lycopene for tomatoes.

In Figure 4 we plot PRI against carotenoids and NDVI against chlorophylls. Both indices seem to have a high correlation with the corresponding pigment, which is not surprising since NDVI uses the wavelength of $780 \mathrm{~nm}$, which is the peak of chlorophyll absorption (Figure 1) and PRI the $531 \mathrm{~nm}$, which highly corresponds to the carotenoid absorption. However, these chosen wavelengths also include absorption of other features, as shown in Figure 1. This illustrates the dependence of indices on their selected wavelengths, meaning that they might not perform well over a range of species, leaves with considerably different ratios of pigment concentrations, and also over different seasons (Karnieli et al., 2010; Garbulsky et al., 2011). We have shown that RT models can be applied to greenhouse crops. Their added value lies in non-destructive estimation of pigment concentrations, mechanistic description and estimation of leaf light absorption. 


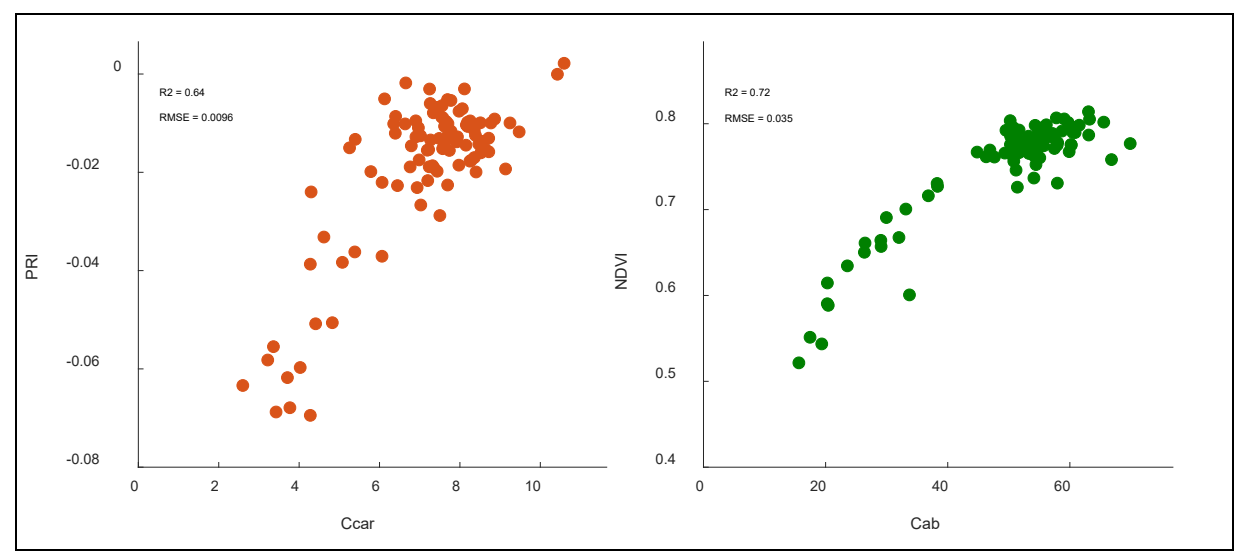

Figure 4. PRI (left) and NDVI (right) plotted against carotenoids and chlorophylls, respectively (both in $\mathrm{g} \mathrm{cm}^{-2}$ ). PRI and NDVI were calculated following Equations 1 and 2.

\section{CONCLUSIONS}

The following conclusions can be drawn from the study:

- Traditional indices provide limited information on crop pigments;

- Radiative transfer (RT) models provide an accurate method for non-destructive estimation of tomato leaf chlorophyll and carotenoid concentrations;

- RT models can be extended to contain desired leaf absorption features of interest, such as sugars.

\section{ACKNOWLEDGEMENTS}

The authors want to thank all their colleagues and students for their assistance in the data collection and the research for this paper.

\section{Literature cited}

Ač, A., Malenovský, Z., Olejníčková, J., Gallé, A., Rascher, U., and Mohammed, G. (2015). Meta-analysis assessing potential of steady-state chlorophyll fluorescence for remote sensing detection of plant water, temperature and nitrogen stress. Remote Sens. Environ. 168, 420-436 https://doi.org/10.1016/j.rse.2015.07.022.

Demarez, V. (1999). Seasonal variation of leaf chlorophyll content of a temperate forest. Inversion of the PROSPECT model. Int. J. Remote Sens. 20 (5), 879-894 https://doi.org/10.1080/014311699212975.

Dieleman, A., Polder, G., Meinen, E., Van Arkel, J., and Weerheim, K. (2018). Klimaat sturen op de inhoud van het blad. Rapport WPR-770.

Drusch, M., Moreno, J., Del Bello, U., Franco, R., Goulas, Y., Huth, A., Kraft, S., Middleton, E.M., Miglietta, F., Mohammed, G., et al. (2017). The FLuorescence EXplorer Mission Concept-ESA's Earth Explorer 8. IEEE Trans. Geosci. Remote Sens. 55 (3), 1273-1284 https://doi.org/10.1109/TGRS.2016.2621820.

Féret, J.-B., Gitelson, A.A., Noble, S.D., and Jacquemoud, S. (2017). PROSPECT-D: towards modeling leaf optical properties through a complete lifecycle. Remote Sens. Environ. 193, 204-215 https://doi.org/10.1016/j.rse. 2017.03.004.

Garbulsky, M.F., Peñuelas, J., Gamon, J., Inoue, Y., and Filella, I. (2011). The photochemical reflectance index (PRI) and the remote sensing of leaf, canopy and ecosystem radiation use efficiencies. A review and meta-analysis. Remote Sens. Environ. 115 (2), 281-297 https://doi.org/10.1016/j.rse.2010.08.023.

Jacquemoud, S., Verhoef, W., Baret, F., Bacour, C., Zarco-Tejada, P.J., Asner, G.P., François, C., and Ustin, S.L. (2009). 'PROSPECT+SAIL models: a review of use for vegetation characterization. Remote Sens. Environ. 113 (Suppl 0), S56-S66 https://doi.org/10.1016/j.rse.2008.01.026.

Karnieli, A., Agam, N., Pinker, R.T., Anderson, M., Imhoff, M.L., Gutman, G.G., Panov, N., and Goldberg, A. (2010). Use of NDVI and land surface temperature for drought assessment: merits and limitations. J. Clim. 23 (3), 618-633 https://doi.org/10.1175/2009JCLI2900.1.

Mahlein, A.K., Rumpf, T., Welke, P., Dehne, H.W., Plümer, L., Steiner, U., and Oerke, E.C. (2013). Development of spectral indices for detecting and identifying plant diseases. Remote Sens. Environ. 128, 21-30 
https://doi.org/10.1016/j.rse.2012.09.019.

Sims, D.A., and Gamon, J.A. (2002). Relationships between leaf pigment content and spectral reflectance across a wide range of species, leaf structures and developmental stages. Remote Sens. Environ. 81 (2-3), 337-354 https://doi.org/10.1016/S0034-4257(02)00010-X.

Stylinski, C., Gamon, J., and Oechel, W. (2002). Seasonal patterns of reflectance indices, carotenoid pigments and photosynthesis of evergreen chaparral species. Oecologia 131 (3), 366-374 https://doi.org/10.1007/s00442-0020905-9. PubMed

Tremblay, N., Wang, Z., and Cerovic, Z.G. (2012). Sensing crop nitrogen status with fluorescence indicators. A review. Agron. Sustain. Dev. 32 (2), 451-464 https://doi.org/10.1007/s13593-011-0041-1.

Van der Tol, C., Verhoef, W., Timmermans, J., Verhoef, A., and Su, Z. (2009). An integrated model of soil-canopy spectral radiances, photosynthesis, fluorescence, temperature and energy balance. Biogeosciences 6 (12), 31093129 https://doi.org/10.5194/bg-6-3109-2009.

Vilfan, N., Van der Tol, C., Muller, O., Rascher, U., and Verhoef, W. (2016). Fluspect-B: a model for leaf fluorescence, reflectance and transmittance spectra. Remote Sens. Environ. 186, 596-615 https://doi.org/10.1016/j.rse.2016. 09.017.

Vilfan, N., Van der Tol, C., Yang, P., Wyber, R., Malenovský, Z., Robinson, S.A., and Verhoef, W. (2018). Extending Fluspect to simulate xanthophyll driven leaf reflectance dynamics. Remote Sens. Environ. 211, 345-356 https://doi.org/10.1016/j.rse.2018.04.012.

Wieneke, S., Ahrends, H., Damm, A., Pinto, F., Stadler, A., Rossini, M., and Rascher, U. (2016). Airborne based spectroscopy of red and far-red sun-induced chlorophyll fluorescence: implications for improved estimates of gross primary productivity. Remote Sens. Environ. 184, 654-667 https://doi.org/10.1016/j.rse.2016.07.025.

Zhang, Y., Huang, J., Wang, F., Blackburn, G.A., Zhang, H.K., Wang, X., Wei, C., Zhang, K., and Wei, C. (2017). An extended PROSPECT: advance in the leaf optical properties model separating total chlorophylls into chlorophyll a and b. Sci Rep 7 (1), 6429 https://doi.org/10.1038/s41598-017-06694-y. PubMed 